Summary This study evaluated the effects of voltage on rise time and light output from incandescent brake lamps for a range of voltages representing realistic values for large trucks. The findings indicate that, relative to nominal voltage of $12.8 \mathrm{~V}$, realistic voltages for large trucks lead to significant increases in rise time and to decreases in light output. At $9 \mathrm{~V}$, for example, $90 \%$ of the asymptotic light output is reached about $113 \mathrm{~ms}$ later than at $12.8 \mathrm{~V}$, and the asymptotic light output is about $28 \%$ of the output at $12.8 \mathrm{~V}$. Analogous comparisons of $6 \mathrm{~V}$ with $12.8 \mathrm{~V}$ indicate an increase in the rise time to $90 \%$ of asymptotic light output of about $316 \mathrm{~ms}$ and a decrease in asymptotic light output to about $5 \%$. The changes obtained in rise time and light output of incandescent lamps as a function of voltage are of practical importance because they can be expected to increase following drivers' reaction times to brake signals and to increase the frequency of missed signals.

\title{
Effects of voltage drop on the rise time and light output of incandescent brake lamps on trucks
}

\author{
M Sivak $\mathrm{PhD}$, T Sato and $\mathrm{MJ}$ Flannagan $\mathrm{PhD}$ \\ The University of Michigan Transportation Research Institute, 2901 Baxter Road, Ann Arbor, Michigan 48109-2150, USA
}

Received 22 July 1993, in final form 4 January 1994

\section{Introduction}

This study dealt with the effects of voltage drop on rise time and light output of incandescent brake lamps. Even under nominal conditions when $12.8 \mathrm{~V}$ is applied, incandescent brake lamps have a relatively slow rise time. No measurable light is emitted for about $50 \mathrm{~ms}$, and about a quarter of a second is required for the filament to reach $90 \%$ of the asymptotic output ${ }^{(1)}$. This slow rise time of conventional brake lamps can cause important delays in warning information to following drivers ${ }^{(1,2)}$.

The problem is aggravated as the voltage is reduced from the nominal $12.8 \mathrm{~V}$. Voltage drop is particularly a problem in large trucks (lorries). A recent survey performed for the US Department of Transportation ${ }^{(3)}$ examined the issue of voltage drop in a sample of 546 large trucks. The results at 700 rpm (normal idle) are shown in Table 1. (The voltages at $1100 \mathrm{rpm}$ were only slightly higher. For example, the mean for doubles at $11000 \mathrm{rpm}$ was $9.9 \mathrm{~V}$, compared to $9.8 \mathrm{~V}$ at 700 rpm.)

Table 1 Voltage at brake lamps (V) for a sample of 546 large trucks (adapted from Copenhaver et al.(3)

\begin{tabular}{lrlll}
\hline Vehicle type & Minimum & Maximum & Mean & $\begin{array}{l}\text { Standard } \\
\text { deviation }\end{array}$ \\
\hline Dumptrucks & 10.3 & 13.1 & 12.2 & 0.8 \\
Vans & 8.8 & 13.8 & 11.6 & 1.0 \\
Tanks & 7.5 & 13.4 & 11.5 & 1.2 \\
Flatbeds & 6.5 & 13.2 & 11.4 & 1.2 \\
Doubles & 6.0 & 12.4 & 9.8 & 1.5 \\
Triples & 5.5 & 11.1 & 8.4 & 1.6 \\
\hline
\end{tabular}

The major factors affecting voltage drop across any electrical circuit are the effective length of the cable, wire gauge (size), and connector/wiring integrity ${ }^{(4)}$. A recent investigation found that low voltages in large trucks were primarily due to undersized wiring(4).

The present study evaluated the effects of voltage drop on rise time and light output for a range of voltages representing real- istic in-traffic values for large trucks. On the basis of the survey discussed above ${ }^{(3)}$, the range of voltages used was from $12.8 \mathrm{~V}$ to $6 \mathrm{~V}$.

\section{Method}

\subsection{Brake lamp}

We used one brake lamp for all measurements. The lamp had a standard incandescent light source, No. 1157. This light source has two filaments; the voltage was applied to the brake filament.

\subsection{Voltages}

A regulated power supply was used to generate one of eight different voltages: $12.8,12,11,10,9,8,7$, and $6 \mathrm{~V}$.

\subsection{Procedure}

Light output (after it had passed through the red lens of the lamp) was measured by a Minolta illuminance meter, Model $\mathrm{T}-1$, positioned $1 \mathrm{~m}$ from the brake lamp. The voltage and illuminance information were fed into an oscilloscope. The images of the changes of voltage and light output were photographed for later analyses. The lamp was left in the off state for one minute to cool down between measurements.

\section{Results}

The light output curves by voltage (normalised to the output at $12.8 \mathrm{~V}$ ) are presented in Figure 1. Table 2 lists the delay in reaching the $90 \%$ level of asymptotic output as a function of voltage. Table 3 lists the asymptotic light output as a function of voltage.

\section{Conclusions}

The present findings indicate that, relative to a nominal voltage of $12.8 \mathrm{~V}$, in-service voltages of large trucks lead to significant increases in rise time and decreases in light output from incandescent brake lamps. At $9 \mathrm{~V}$, for example, $90 \%$ of the asymptotic light output is reached $113 \mathrm{~ms}$ later than at $12.8 \mathrm{~V}$, and the asymptotic light output is $28 \%$ of the maximum at 


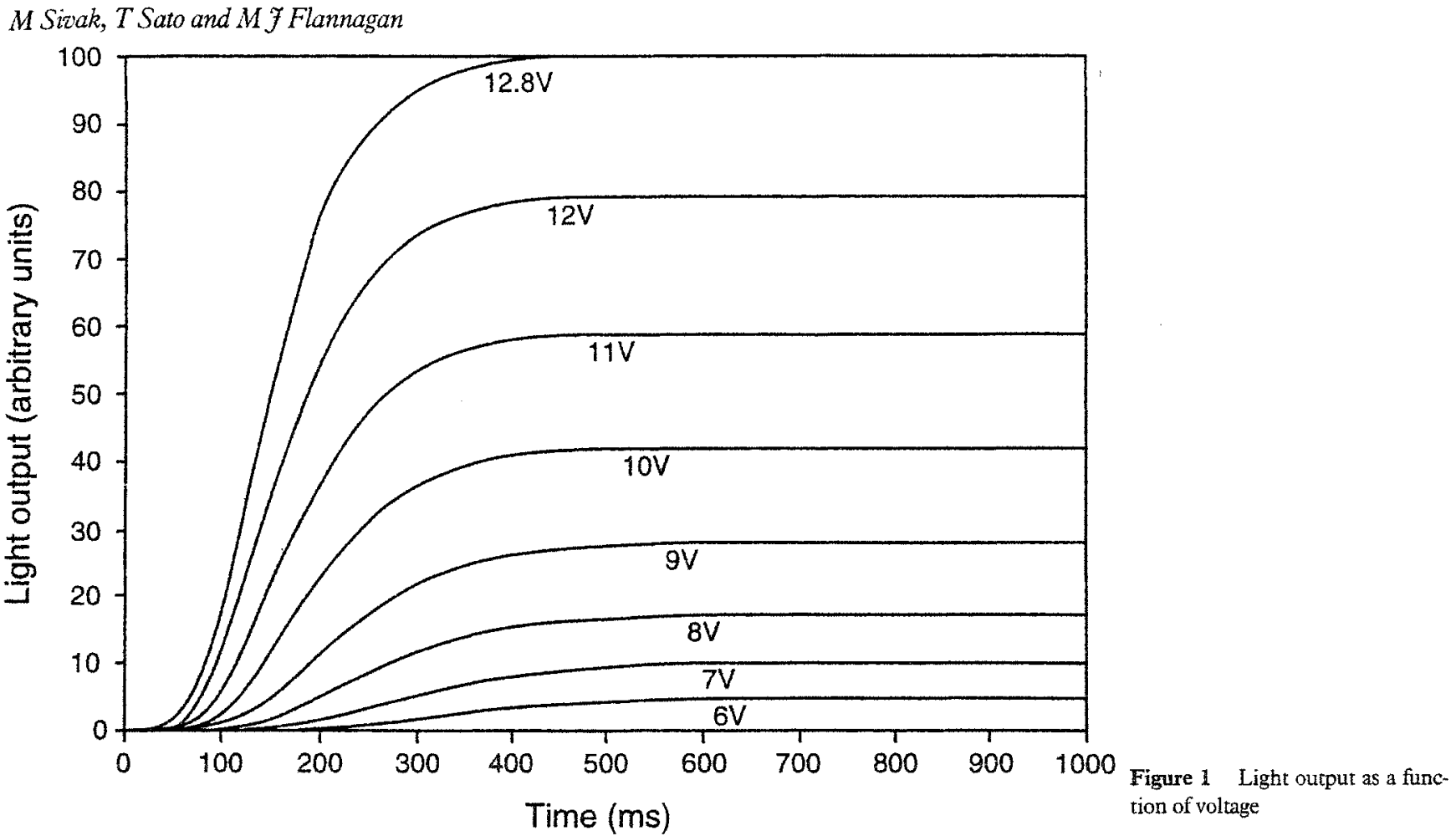

Time (ms)

Table 2 Delay in reaching $90 \%$ of asymptotic light output by voltage

\begin{tabular}{ll}
\hline Voltage (V) & Delay (ms) \\
\hline 12.8 & 259 \\
12 & 282 \\
11 & 294 \\
10 & 320 \\
9 & 372 \\
8 & 410 \\
7 & 487 \\
6 & 575 \\
\hline
\end{tabular}

$12.8 \mathrm{~V}$. Analogous comparisons of $6 \mathrm{~V}$ with $12.8 \mathrm{~V}$ indicate an increase in rise time of $316 \mathrm{~ms}$ and a decrease in light output to $5 \%$.

Reaction time to the onset of light stimuli increases with either an increase in the rise time of the stimulus(1), or a decrease in the intensity of the stimulus ${ }^{(5)}$. Consequently, the changes obtained in rise time and light output of incandescent lamps as functions of voltage are of practical importance. Reduced voltage can be expected to cause an increase in following drivers' reaction times to brake signals. Furthermore, the reduced light output will likely result in an increase in the frequency of missed brake signals.

\section{Acknowledgements}

Appreciation is extended to the members of The University of Michigan Industry Affiliation Program for Human Factors in Transportation Safety for support of this research. The current members are Bosch, Carello Lighting, Chrysler, Donnelly, Ford (Plastic and Trim Products Division), GM (Inland Fisher Guide Division), Ichikoh Industries, Koito Manufacturing, LESCOA, Libbey-Owens-Ford, Muth Advanced Technologies, Osram Sylvania, Philips Lighting, PPG Industries, Stanley Electric, Valeo, Wagner Lighting, and $3 \mathrm{M}$.

\section{References}

1 Flannagan $M J$ and Sivak $M$ An improved braking indicator (SAE Technical Paper Series \#890189) (Warrendale, PA: Sociery of Automotive Engineers) (1989)

2 Sivak $M$ and Flannagan $M J$ A fast rise brake lamp as a collision-prevention device Ergonomics 36(4) 391-395 (1993)

3 Copenhaver $M M$, Guerrier J and Ching $H$ Photometric and electrical performance characteristics of rear lighting equipment on in service truck trailers (Report No. DOT HS 807 845) (Washington, DC: US Department of Transportation) (1990)

4 Lesesky A and Loughran T J An analysis and investigation of tractor and trailer electrical system capabilities (Report No. DOT HS 809 076) (Washington, DC: US Department of Transportation) (1993)

5 Teichner $W$ and Krebs $M$ The laws of simple visual reaction time Psychological Review 79(4) 344-358 (1972) 